\title{
Fructose metabolism in the human erythrocyte
}

\author{
Phosphorylation to fructose 3-phosphate
}

\author{
Aqqaluk PETERSEN, ${ }^{*} \ddagger$ Francis KAPPLER, $\dagger$ Benjamin S. SZWERGOLD $\dagger$ and Truman R. BROWN $\dagger$ \\ *Department of Clinical Biochemistry, KK-3011, State University Hospital (Rigshospitalet), Blegdamsvej 9, \\ DK-2100 Copenhagen, Denmark, and †Department of NMR and Medical Spectroscopy, \\ Fox Chase Cancer Center, Philadelphia, PA 19111, U.S.A.
}

\begin{abstract}
In human erythrocytes, the first step in the metabolism of fructose is generally thought to be phosphorylation to fructose 6-phosphate catalysed by hexokinase. In variance with this assumption, we show here that fructose in these cells is metabolized primarily to fructose 3-phosphate by a specific 3-phosphokinase. This process has an overall estimated $K_{\mathrm{m}}$ of $30 \mathrm{~mm}$ with respect to extracellular fructose and an apparent $V_{\max }$ of $0.6 \mu \mathrm{mol} / \mathrm{h}$ per $\mathrm{ml}$. At a fixed concentration of fructose in the medium, the accumulation of fructose 3-phosphate was linearly dependent on the duration of incubation up to $5 \mathrm{~h}$ and was not affected by glucose. Once accumulated, fructose 3-phosphate appears to be degraded and/or relatively slowly metabolized, decreasing by only $\sim 30 \%$ after a $12 \mathrm{~h}$ incubation in a fructose-free medium.
\end{abstract}

\section{INTRODUCTION}

The metabolism of fructose in humans is known to occur primarily in the liver, gut and kidneys (for reviews, see [1,2]). In these tissues fructose is phosphorylated by fructokinase to fructose 1-phosphate, which is cleaved by aldolase (type B) to glyceraldehyde and dihydroxyacetone phosphate. Glyceraldehyde is subsequently phosphorylated by triokinase, after which the triose phosphates are metabolized in the glycolyticgluconeogenic pathway $[1,2]$. In spite of the consensus on this general view of fructose metabolism, animal and human studies have repeatedly shown that variable amounts of orally or intravenously administered fructose are not accounted for by these classic tissues of fructose metabolism [3-7]. In one study, as much as $50 \%$ of intravenously infused fructose $(30 \mathrm{~g} / \mathrm{h})$ was not metabolized by the splanchnic tissues [4]. This peripheral utilization of fructose is also supported by data from subjects with essential fructosuria, who have a deficiency of the hepatic fructokinase. In spite of this defect these individuals retain as much as $90 \%$ of a bolus of fructose [2]. The metabolism of fructose in peripheral tissues is usually explained by the phosphorylation of fructose to fructose 6-phosphate by hexokinase, although the affinity of this enzyme for fructose is about 10 -fold lower than for glucose [1,2,5-7]. Recently Szwergold et al. [8] reported the identification of a novel fructose phosphate in the lens of diabetic rats, fructose 3-phosphate (Fru-3-P). Fru3-P and its decomposition product 3-deoxyglucosone were shown to be potent protein-glycosylating agents and to be implicated in the development of cataracts in the lenses of these animals [8]. Subsequently Fru-3- $P$ was identified in erythrocytes of normal and diabetic humans, where it occurred at a concentration of $13 \mu \mathrm{M}$ in normal subjects [9]. Furthermore, the enzymic activity responsible for the direct phosphorylation of fructose to Fru-3$P$ was partially purified by high-salt treatment of erythrocyte ghosts, suggesting that the enzyme is a peripheral membrane protein [9]. Here we show, using ${ }^{31}$ P-n.m.r. spectroscopy, that in intact erythrocytes Fru-3-P is the dominant phosphorylated metabolite of exogenous fructose.

\section{MATERIALS AND METHODS}

\section{Erythrocytes}

Venous blood was collected from normal human volunteers after venipuncture into heparinized tubes. The tubes were centrifuged at $1000 \mathrm{~g}$ for $10 \mathrm{~min}$ at $4{ }^{\circ} \mathrm{C}$, after which the plasma and the buffy coat were aspirated and discarded. The erythrocytes were washed three times in a $\mathrm{HCO}_{3}{ }^{-} / \mathrm{CO}_{2}$-buffered Krebs-Ringer solution ( $\mathrm{pH} 7.35-7.40$ ) with $5 \mathrm{mM}$-glucose, the composition of which is given in [10]. The erythrocytes were then pelleted at $10000 \mathrm{~g}$ for $10 \mathrm{~min}$ at $4{ }^{\circ} \mathrm{C}$, and the supernatant was aspirated and discarded. The erythrocyte suspension was then divided into $1.5 \mathrm{ml}$ portions in $40 \mathrm{ml}$ screw-cap centrifuge tubes, before dilution with the same buffer as above but containing variable amounts of fructose and glucose as indicated in the text and the legends to the Figures. This assured a haematocrit $<5 \%$ and a constant $\mathrm{pH}$ at 7.35-7.40 in the suspension during the incubation. The suspensions were then incubated in a shaking water bath at $37^{\circ} \mathrm{C}$ for the indicated times, after which the erythrocytes were concentrated for the n.m.r. measurement by centrifugation at $10000 \mathrm{~g}$ for $5 \mathrm{~min}$ at $4{ }^{\circ} \mathrm{C}$, before transferring to a $1.5 \mathrm{ml} \mathrm{microcell}$ in a standard $10 \mathrm{~mm}$ n.m.r. tube. For some of the experiments, erythrocytes were extracted with $\mathrm{HClO}_{4}$ after incubation. The extracts were freeze-dried before resuspension for the n.m.r. measurements.

\section{Identification of Fru-3-P}

Erythrocytes $(10 \mathrm{ml})$ preincubated with $30 \mathrm{~mm}$-fructose for $3 \mathrm{~h}$ were extracted with $\mathrm{HClO}_{4}$ as previously described [9]. The neutralized extract was then analysed by ${ }^{31}$ P-n.m.r. before (Fig. $2 a$ ) and after (Fig. $2 b$ ) addition of synthetic Fru-3-P [8].

\section{${ }^{31}$ P-n.m.r. measurements}

These were performed at ambient temperature $\left(25^{\circ} \mathrm{C}\right)$ on a Bruker AM-400 spectrometer at $161.98 \mathrm{MHz}$ by using a pulse angle of $60^{\circ}$ with a relaxation delay of $1.5 \mathrm{~s}$. Variable numbers of scans were accumulated, depending on the concentration of Fru3-P attained, but no measurement lasted longer than $30 \mathrm{~min}$. The 
concentration of Fru-3-P was estimated by using the peak area normalized to the 3-phosphate peak of 2,3-bisphosphoglycerate (2,3-BPG). In the reported kinetic experiments, the Fru-3-P was normalized to the actual 2,3-BPG concentration as measured enzymically [11], whereas in the experiments with different volunteers the 2,3-BPG was set to $5.17 \mathrm{~mm}$ [12]. Some of the experiments involving $\mathrm{HClO}_{4}$ extracts of erythrocytes were performed on a Bruker AM-250 spectrometer at $101.3 \mathrm{MHz}$ by using the same parameters as indicated above. All concentrations given are expressed as $\mathrm{mmol} / \mathrm{l}$ of erythrocytes.

\section{RESULTS}

Incubation of human erythrocytes with $30 \mathrm{~mm}$-fructose led to an accumulation of a large phosphomonoester peak at 5.7 p.p.m. in the ${ }^{31} \mathrm{P}$-n.m.r. spectrum (Fig. 1). The peak was identified as fructose 3-phosphate by adding authentic Fru-3-P to a neutralized $\mathrm{HClO}_{4}$ extract of erythrocytes preincubated in fructose (Figs. $2 a$ and $2 b$ ).

To investigate the kinetics of this accumulation of Fru-3-P, erythrocytes were incubated with different concentrations of

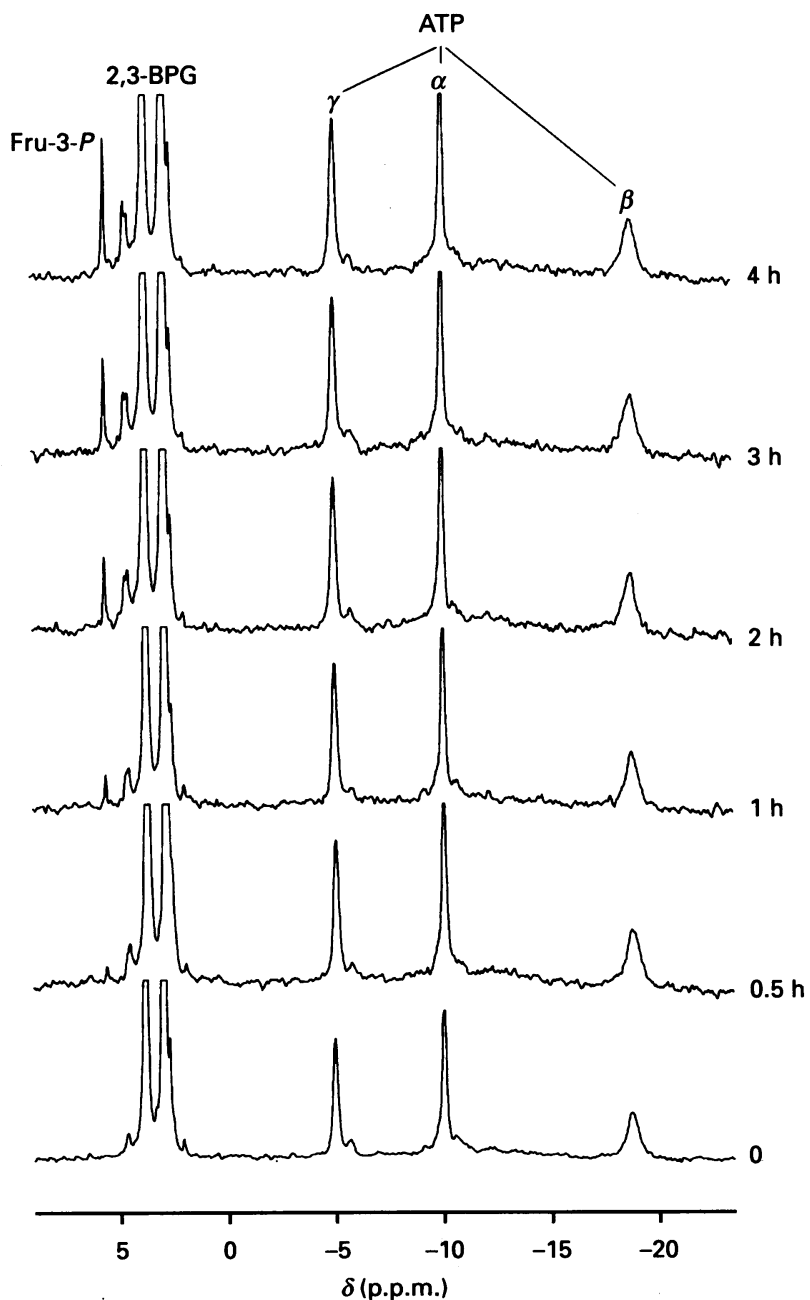

Fig. 1. ${ }^{1} \mathrm{H}$-decoupled ${ }^{31} \mathrm{P}$-n.m.r. spectra at $162 \mathrm{MHz}$ of human erythrocytes incubated for the indicated times in a Krebs-Ringer buffer solution, pH 7.40, with $30 \mathrm{~mm}$-fructose and $5 \mathrm{~mm}$-glucose at $37^{\circ} \mathrm{C}$

The metabolites identified are Fru-3-P, 2,3-BPG and ATP, where the $\alpha$-, $\beta$ - and $\gamma$-phosphate groups are indicated.
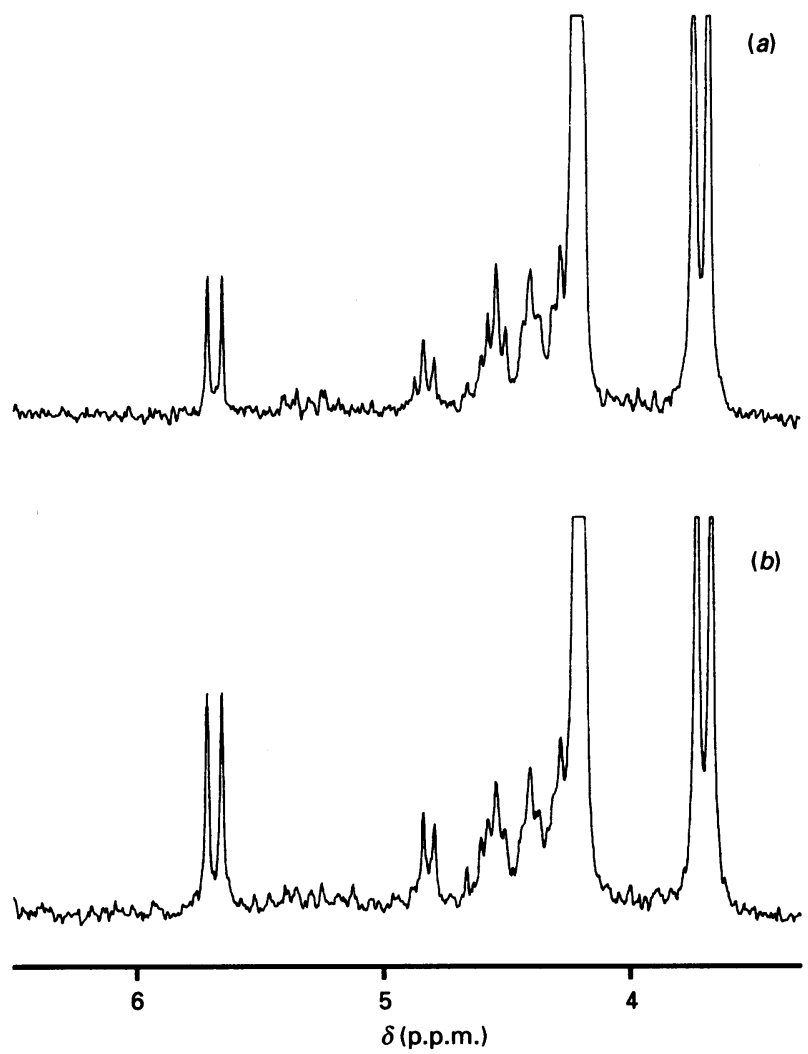

Fig. 2. The 3.3-6.5 p.p.m. region of a ${ }^{1} \mathbf{H}$-coupled ${ }^{31} \mathbf{P}$-n.m.r. spectrum of an extract of erythrocytes preincubated with $30 \mathrm{~mm}$-fructose for $4 \mathrm{~h},(a)$ alone, and (b) after addition of synthetic Fru-3-P to the extract

Note that the doublet at 5.7 p.p.m. only represents the $\beta$-pyranose forms of Fru-3-P, whereas the $\beta$-furanose forms resonate around 4.8 p.p.m. here [8]. The apparent triplet at 4.8 p.p.m. in $(a)$ is a doublet corresponding to the $\beta$-furanose of Fru-3-P and an unrelated singlet that is buried when synthetic Fru-3-P is added $(b)$.

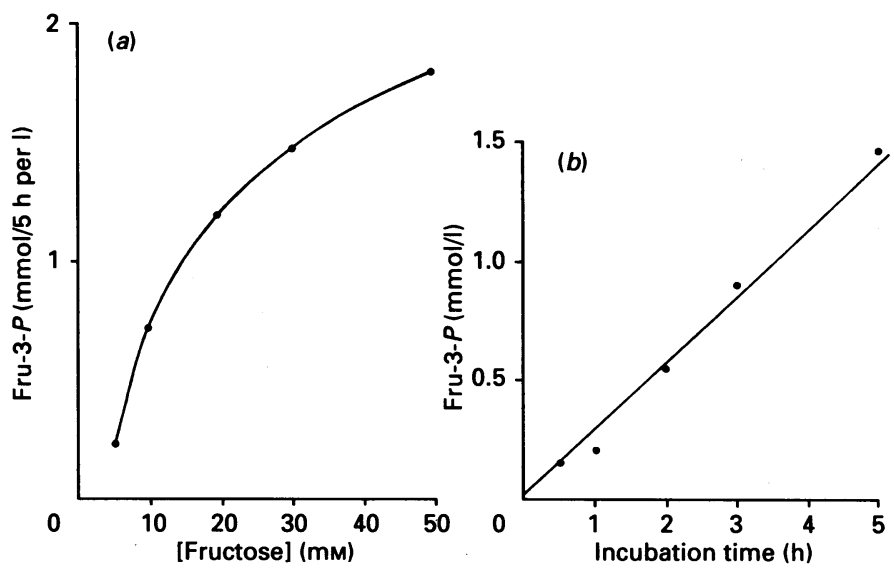

Fig. 3. Concentrations of Fru-3-P in human erythrocytes after incubation for $5 \mathrm{~h}$ in various concentrations of fructose $(a)$ and after incubating erythrocytes in $30 \mathrm{mM}$-fructose for the indicated times (b)

fructose for $5 \mathrm{~h}$. The results with erythrocytes from one subject are shown in Fig. 3(a), where the extracellular fructose concentration was varied from $5 \mathrm{~mm}$ to $50 \mathrm{~mm}$. The accumulation of Fru-3- $P$ has an apparent $K_{\mathrm{m}}$ of $30 \mathrm{~mm}$ with respect to the external fructose concentration and an apparent $V_{\max }$. of Fru-3-P formation of $0.6 \mu \mathrm{mol} / \mathrm{h}$ per $\mathrm{ml}$. Similar incubations of 


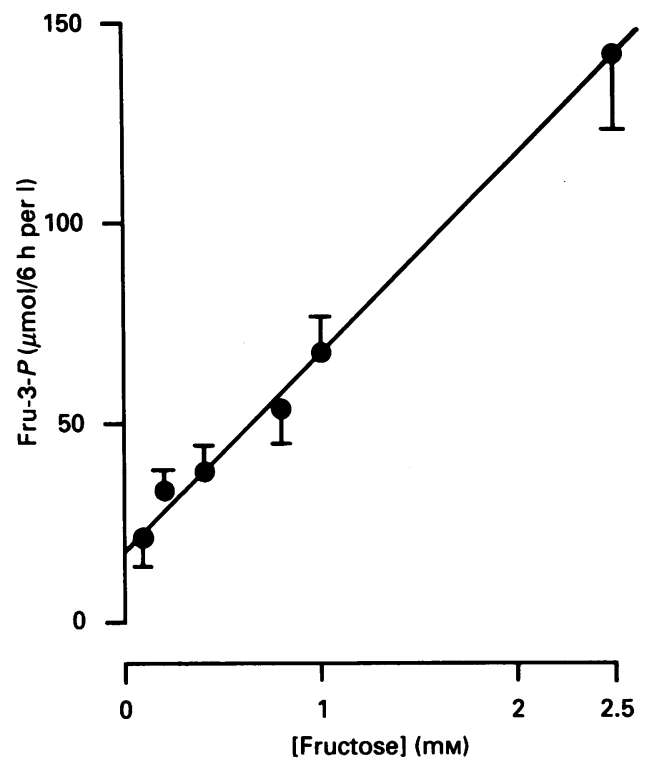

Fig. 4. Concentrations of Fru-3-P in human erythrocytes after incubation for $6 \mathrm{~h}$ at the indicated concentrations of fructose

In all incubations $5 \mathrm{~mm}$-glucose was included. The bars indicate S.D. values for 4-5 individual incubations from different donors.

erythrocytes from another subject yielded essentially the same results.

The time course of the Fru-3- $P$ accumulation was investigated at the constant extracellular fructose concentration of $30 \mathrm{~mm}$ (Fig. $3 b$ ); as shown, the accumulation of Fru-3-P is linearly dependent on the duration of incubation. To investigate the variability of the rate of formation of Fru-3- $P$, erythrocytes were isolated from eight different subjects and incubated for $3 \mathrm{~h}$ at an extracellular fructose concentration of $30 \mathrm{~mm}$. The rate of accumulation of Fru-3-P was found to be $0.25 \pm 0.03$ (s.D.) $\mu \mathrm{mol} / \mathrm{h}$ per $\mathrm{ml}$ of erythrocytes $(n=8)$.

To investigate the phosphorylation to Fru-3-P at more physiological levels of fructose, erythrocytes were incubated with $0.1-2.5 \mathrm{~mm}$-fructose for $6 \mathrm{~h}$ (Fig. 4). In all incubations $5 \mathrm{~mm}$ glucose was included. As expected at these levels of fructose, there is a linear relationship between the rate of Fru-3-P formation and the extracellular levels of fructose (Fig. 4).

The peripheral utilization of fructose is usually inhibited by glucose, as fructose is envisaged to be phosphorylated by hexokinase [1,2,5-7]. Using $10 \mathrm{~mm}$-fructose, we investigated whether $5 \mathrm{~mm}$-glucose inhibited the accumulation of Fru-3-P in human erythrocytes. The results with or without glucose were identical, producing $0.06 \pm 0.02$ (S.E.M.) $\mu \mathrm{mol}$ of Fru-3-P/h per $\mathrm{ml}(n=4)$.

The metabolic fate of Fru-3- $P$ in erythrocytes was investigated by preloading erythrocytes with $30 \mathrm{~mm}$-fructose for $3 \mathrm{~h}$, and then washing the cells in the Krebs-Ringer buffer solution with $5 \mathrm{~mm}$ glucose and resuspending them in the same buffer for further incubation. The Fru-3- $P$ concentration decreased from an initial value of $0.60 \pm 0.05$ (S.E.M.) $\mathrm{mmol} / 1$ to $0.41 \pm 0.05$ (S.E.M.) $\mathrm{mmol} / 1$ $(n=7)$ after $12 \mathrm{~h}$ in the fructose-free medium.

\section{DISCUSSION}

The metabolism of fructose in human erythrocytes has only been investigated systematically once [13], although fructose has been known to be metabolized by erythrocytes for some time [5,14-16]. Furthermore, fructose has been suggested as a possible nutrient in storage and rejuvenation solutions for erythrocytes
$[17,18]$. Fructose could be metabolized by erythrocytes in place of glucose, although the utilization of the sugar was depressed when glucose was present simultaneously $[5,13,16]$. The data were interpreted in terms of fructose being phosphorylated by hexokinase to fructose 6-phosphate and subsequently incorporated into the glycolytic pathway [13]. However, especially at higher fructose concentrations $(>2.5 \mathrm{~mm})$, there was an unexplained disappearance of fructose that was not accounted for by the appearance of lactate and could not be accounted for by the pentose phosphate shunt [13].

Our results explain this discrepancy as fructose is primarily phosphorylated to Fru-3-P (Fig. 1) [9] and is independent of glucose. We did not attempt to quantify the relative contributions of the hexokinase reaction/glycolytic pathway and the phosphorylation of fructose to Fru-3-P. Previous studies suggest that very little fructose is phosphorylated by hexokinase in the presence of glucose, as the affinity of hexokinase for fructose is much lower than for glucose [13].

The accumulation for Fru-3- $P$ in human eythrocytes was found to have a $K_{\mathrm{m}}$ of $30 \mathrm{~mm}$ with respect to external fructose (Fig. 3). Even low, more physiological, levels of fructose $(0.1-2.5 \mathrm{~mm})$ in the presence of $5 \mathrm{~mm}$-glucose resulted in the accumulation of Fru-3-P (Fig. 4). Combined with the very slow further metabolism of Fru-3-P (see the Results section), these results may be interpreted by viewing this reaction as an overflow pathway of fructose metabolism. Another possibility is that fructose is not the natural substrate for the reaction. The metabolic fate of Fru-3-P is at present unknown, although the concentrations of Fru-3- $P$ in preloaded erythrocytes decreased to about $70 \%$ of the initial value after $12 \mathrm{~h}$ in a fructose-free medium (see the Results section). Close inspections of the ${ }^{31} \mathrm{P}$ n.m.r. spectra did not reveal any new phosphorus resonance as compared with ${ }^{31}$ P-n.m.r. spectra of a glucose control (results not shown). These results should, of course, be interpreted with caution, as degradation of 2,3-BPG was also evident during the prolonged incubation for $12 \mathrm{~h}$.

Free fructose in erythrocytes is either generated from glucose through the aldose reductase pathway [19] or can be of dietary origin, either as sucrose or free fructose [20]. The concentration of fructose in fasting human plasma is relatively low and has been measured to be $31 \mu \mathrm{M}$ [21], although the concentration can increase to $0.5-2 \mathrm{mM}$ after an oral or intravenous bolus of fructose $[3,4,6,7,22]$. There is an ongoing discussion among diabetologists whether fructose should be included in the diet of diabetic patients, especially in view of the recent findings that fructose does not seem to have adverse effects on glycaemic control [23-28]. Furthermore, recent results indicate that low concentrations of fructose stimulate the phosphorylation of glucose in the mammalian liver and pancreatic islets [29,30]. In view of the potent protein-glycosylating property of Fru-3-P and its degradation product, 3-deoxyglucosone [9], and the possible involvement of protein glycosylation in the etiology of long-term diabetic complications [31-33], the use of fructose in diabetics should be cautioned against. In this context it is noteworthy that, in a recent controlled clinical study, sural nerve fructose concentration was positively correlated with the development of peripheral neuropathy [34]. Beside human erythrocytes, Fru-3-P has also been identified in mammalian lenses, sciatic nerve and seminal vesicles [8]. Insofar as these results from erythrocytes can be extrapolated to other tissues, elevated plasma concentration of fructose may result in an increased concentration of Fru-3- $P$, especially in view of the relatively low fructose clearance by the classic tissues of fructose metabolism (3-4 h after an oral bolus). Thus erythrocytes and the other tissues where Fru-3- $P$ has been found may account for a significant part of the non-hepatic clearance of fructose. 
In conclusion, we have shown that erythrocytes metabolize fructose very actively to Fru-3- $P$, a potent protein-glycosylating agent. Insofar as these results can be extrapolated to other tissues, this reaction represents an alternative and potentially harmful pathway of fructose metabolism in humans.

This research was supported by the Benzon Foundation, the Danish Medical Research Council, and the Novo Foundation, Copenhagen, Denmark, by N.I.H. grants EY-08223, EY-08414, CA-06927, and by the Commonwealth of Pennsylvania. The volunteers who donated their blood are warmly thanked. A.P. acknowledges the technical assistance of $\mathrm{Al}$ Goll, Dave Maleh and Lone Olsen, and the generous support of J. F. Rehfeld. The secretarial assistance of Charlotte Vienberg is gratefully acknowledged. Some of the n.m.r. experiments were performed at the Department of Chemical Physics, University of Copenhagen, Denmark, where Dr. Kjeld Schaumburg kindly allowed the use of the spectrometer.

\section{REFERENCES}

1. Van den Berghe, G. (1978) Curr. Top. Cell. Regul. 13, 97-135

2. Gitzelmann, R., Steinmann, B. \& Van den Berghe, G. (1983) in The Metabolic Basis of Inherited Disease (Stanbury, J. B., Wyngaarden, J. B., Fredrickson, D. S., Goldstein, J. L. \& Brown, M. S., eds.), pp. 118-140, McGraw-Hill, New York

3. Niewoehner, C. B., Gilboe, D. P., Nuttall, G. A. \& Nuttall, F. Q. (1984) Am. J. Physiol. 247, E505-E512

4. Wolfe, B. M., Ahuja, S. P. \& Marliss, E. B. (1975) J. Clin. Invest. 56, 970-977

5. Froesch, E. R. \& Ginsberg, J. L. (1962) J. Biol. Chem. 237, 2917-2924

6. Niewoehner, C. B. (1986) J. Am. Coll. Nutr. 5, 443-450

7. Roch-Norlund, A. E., Hultman, E. \& Nilsson, L. H. (1972) Acta Med. Scand. Suppl. 542, 181-186

8. Szwergold, B. S., Kappler, F. \& Brown, T. R. (1990) Science 247, 451-454

9. Petersen, A., Szwergold, B. S., Kappler, F., Weingarten, M. \& Brown, T. R. (1990) J. Biol. Chem. 265, 17724-17727

10. Petersen, A., Pedersen, E. J. \& Quistorff, B. (1989) Biochim. Biophys. Acta 1012, 267-271

11. Ericsson, A. \& De Verdier, C.-H. (1972) Scand. J. Clin. Lab. Invest. 29, 85-90

Received 1 May 1991/13 December 1991; accepted 2 January 1992
12. Maida, N., Chang, H., Benesch, R. \& Benesch, R. E. (1971) N. Engl. J. Med. 284, 1239-1242

13. Moses, S. W. \& Bashan, N. (1974) Isr. J. Med. Sci. 10, 707-711

14. Michaelis, L. \& Solomon, A. K. (1929-30) J. Gen. Physiol. 13, 683-693

15. Valentine, W. N., Oski, F. A., Paglia, D. E., Bauchan, M. A., Schneider, A. S. \& Naiman, J. C. (1967) N. Engl. J. Med. 276, 1-7

16. Quadflieg, K. H. \& Brand, K. (1977) Acta Biol. Med. Germ. 36, 639-643

17. Dawson, R. B., Levine, Z., Zuck, T., Hershey, R. T. \& Myers, C. (1978) Transfusion 18, 347-352

18. Torrance, J. D. (1973) J. Lab. Clin. Med. 82, 489-499

19. Morrison, A. D., Clements, R. S., Jr., Travis, S. B., Oski, F. \& Winegrad, A. I. (1970) Biochem. Biophys. Res. Commun. 40, 199-205

20. Crapo, P. A. \& Koltermann, O. G. (1984) Am. J. Clin. Nutr. 39, 525-534

21. Aloia, J. F. (1973) J. Lab. Clin. Med. 82, 809-817

22. Sestoft, L. (1985) Acta Anaesthesiol. Scand. 29, 19-29

23. Bantle, J. P., Dawn, C. L., Castle, G. W., Thomas, J. W., Hoogwerf, B. J. \& Goetz, F. C. (1983) N. Engl. J. Med. 209, 7-12

24. Bantle, J. P., Laine, C. L. \& Thomas, J. W. (1986) J. Am. Med. Assoc. 256, 3241-3246

25. Osei, K., Falko, J., Bosseti, B. M. \& Holland, G. C. (1987) Am. J. Med. 83, 249-255

26. Kim, H. S., Paik, H. Y., Lee, K. U., Lee, H. K. \& Min, H. K. (1988) Diabetes Res. Clin. Pract. 4, 281-287

27. Thorburn, A. W., Crapo, P. A., Griver, K., Wallace, P. \& Henry, R. R. (1990) Metab. Clin. Exp. 39, 58-63

28. Grigoresco, C., Rizalka, S. W., Hafton, P., Bornet, F., Fontvielle, A. M., Bros, M., Dauchy, F., Tchobrousky, G. \& Slama, G. (1988) Diabetes Care 11, 546-550

29. Davies, D. R., Detheux, M. \& van Schaftingen, E. (1990) Eur. J. Biochem. 192, 283-289

30. Malaisse, W. J., Malaisse-Lagae, F., Davies, D. R., Vandercammen, A. \& van Schaftingen, E. (1990) Eur. J. Biochem. 190, 539-545

31. Brownlee, M. \& Cerami, A. (1981) Annu. Rev. Biochem. 50, 385-432

32, Bunn, H. F. (1984) Am. J. Med. 70, 325-330

33. Brownlee, M. (1989) in The Maillard Reaction of Aging, Diabetes, and Nutrition (Baynes, J. W. \& Monnier, V. M., eds.), pp. 69-84, Alan R. Liss, New York

34. Dyck, P. J., Zimmerman, B. R., Vilen, T. H., Minnerath, S. R., Karnes, J. L., Yao, J. K. \& Poduslo, J. F. (1988) N. Engl. J. Med. $319,542-548$ 